\title{
Nikolai Ironov: \\ How Neuronets Create Digital Visual Culture
}

\section{Okhvat Kristina}

Ural Federal University, Russia, Ekaterinburg

greendolphin@mail.ru

\begin{abstract}
The article analyses the work of modern neuron networks used for the creation of objects of digital visual culture. "Art" of such neuronets is related to finding unobvious regularities as a result of data processing and compilation of them into a unity. Five categorial grounds allowing understand processes related to specifics of digital culture in general are studied. Analysis enables answering existing questions and identifying new directions for development.
\end{abstract}

Keywords: visual culture, visual image, neuronet, data base

\section{Introduction}

In the conditions of continuous data flow and uninterrupted scientific progress we see increase of a share of digital visual culture and among social networks most popular are those where photos or small videos are published; every day instant messages are more often sent in the form of a graphic icon. A specific of digital visual culture is that an image, not a text symbol, is highlighted. It defines a way of information perception as well as the process of its transfer. And the notion of videocracy, i. e. power of image, video image, in comparison with logocracy, where the power is hold by a word, appears right here [Gabova, 2017].Visual images in modern digital culture are easily known and interpreted. Contrary to the text, image may be read by people from various cultural, language and/ or ethnic groups. Visual language is trans cultural.

Development of computer technologies have assisted strengthening videocracy in culture. Computerization enables users to be attached to a unified symbol system presented as a catalog or data base. Modern arrangements for operations with such a base prove that it is not just an archive, but a resource that may be used in the production of digital visual objects and practices.

How might computer technologies take part in the production of digital visual culture? What arrangement for creation do they attach to? Which 
elements of their "art" may be identified? This article is an attempt to answer these questions.

\section{Neuronet as a generator of digital visual culture}

Since December 2018 Nikolai Ironov has worked in the agency of Artemy Lebedev. Initially he was introduced as a real employee that worked distantly. But in summer 2020 it became known that a designer who has created over 20 commercially implemented projects is a neuronet in fact. A neuronet (or artificial neuron network) is a system of combined and interacting elements built on the principle of biological neurons. Nikolai Ironov is a generative neuronet. It receives some set of random values and then patterns are being searched for in a specified set of data. From the combinations received in different data systems and programs, a generator creates its own variants of compilation. Any compilation is a result of the transition of a catalog as a set of data into a new form.

In the case of Nikolai Ironov the system analyses information on a customer, generates a flow of relevant specimens, generates color schemes, settles composition tasks, creates pattern and 3D models.

"Art" of such a neuronet is in finding unobvious regularities and compilation of them into a unity. For example, if we show to such a neuronet all that an artist has created it may identify manners specific to these works better than professional art experts. Using the same principle, you may teach a neuronet to draw. It may create something "new" based on what it saw. On the one hand, we may say that neuronets, opposite to machine (re)production, may create unique objects as they find unobvious regularities that become a background for a compilation. On the other hand, they are restricted by what is initially inbuilt into a data base, i. e. pre-defined by some catalog that a user specifies.

A person in such a neuronet performs two functions: initially, related to the creation of a network code and running its operation, and at the end, related to interaction with a result (and in the case of Nikolai Ironov, with the selection of a final product). So, the studio of Artemy Lebedev has offered customers several design variants generated by a neuronet.

\section{Data bases as a resource for neuronet "art"}

Data base (or catalog) on the basis of which a neuronet operates is a resource for the generation of new combinations. "A data base - an analog from the computer - era replaces a narrative that has dominated as a key 
for of cultural communication for a long time" [Manovitch, 2018, 270]. Data base as an open system is characterized by not being complete and at any time may be edited. It may not independently organize elements, A neuronet is responsible for their organization.

Since the 19th century, technologies accumulating a large number of materials (photo and audio archives, video archives) were developed. Excessiveness led to a new stage - the necessity to store as well as to organize files among the total variety. Hence, the question is in how to create "new", as well as what to do with already existing?

We may say that "art" of neuronet is a result of the strategy of re-framing and overproduction. The strategy of re-framing and overproduction (or strategy of graphic saturation) is a transition from individual or serial discreet objects to manipulation with populations of images via various selection and "re-framing" methods of already existing material.

A practice of a "ready-made" became the source of this strategy in. Works of M. Duchamp created in the beginning of the 20th century pushed a totally new philosophy and became an 'ancestor' of post - non-classic art. Marcel Duchamp created a "ready-made" presenting utility units in the form of ready-made works. Starting from the second half of the last century, artists started to use strategies of graphic saturation resulting in populations of images except for creation of separate works. Andy Warhol was the first follower of such a strategy and "Brillo Box" created by him is an example. Its appearance became "a Rozetta stone for philosophy, enabling differentiation of two languages: language of art and language of reality" [Danto, 2018, 39].

Since the mid-1950s four strategies of graphic saturation were formulated. David Joselit describes them one by one in "After art". Each strategy is trying to understand processes performing in art as well as in culture in general. The first strategy is re-framing of found material (content) in the space. Under this concept, objects form various configurations where relations between units become more important than the content of each separate unit. This strategy finds itself in the technique of collage where, on the one hand, elements of usual units perform the same functions as traditional art media, and on the other hand, their combination creates new senses that became possible only due to their combination.

The second strategy, described by Joselit - processual content imprinting: a process of "re-framing" - is performed using various arrangements (digital photos, video, copying machine, text files and other facilities). In oth- 
er words, objects receive new forms of existence related to, in particular, digital conversion. Processing of content into live or "virtual" performances is a third strategy of "re-framing": performance is a public creation of an artifact based on the principle of synthesis of art and non-art, some "gestures" not requiring special professional skills and not pretending a long life. Images undergo a change of condition via transposition of events. To explain this strategy, Joselit points to a 'happening' as an example. He noted that happenings initially were held in indefinite, non-theater sites - in warehouses, closed plants, closed shops. Due to that, they smoothly appeared between avant-garde theater and collage, and a spectator there is also a collage meaning that it is "disseminated" in the space.

In conclusion, Joselit points to documentation of content using research as one more key strategy of "graphic saturation". Documenting shall be performed with the purpose of creation of archive works that may function as non-declarative materials. The word "documents" play a key role. During recent decades documents about art are more and more often included in art exhibitions, into sets of art museums together with traditional art works. Thus, documents become one more arrangement of "re-framing" of already existing material.

It is noted, that each of the strategies presented and described by Joselit is connected not with the invention of a new content, but with manipulating its situational (or performative) nature. We are sure, that after we become witnesses to their combination, work as some result of art activity (an object or conceptually performed action) is a synthesis of several strategies. Sometimes it is impossible to make a clear demarcation line.

Use of such strategies in modern culture is explained by a new type of consciousness. It becomes rhizomatic. Rhizomatic consciousness is a simultaneous co-existence of parallel focuses and none of them dominates. Despite its 'kaleidicness', rhizomatic consciousness has a function of formation of a new world picture in culture and demonstrates the elimination of pillars as well as attempts to find new foundations. The (co)-existence of various worlds in each of which have equal rights, appears.

One of the arrangements due to which switching cultural practices into the mode of (re)-production and distribution of data has become possible is computerization. Today computer technologies "cover all stages and steps of production and distribution of cultural objects, including purchase, management, storage and distribution of any types of artifacts as well as all types 
of media: texts, static and dynamic images, sounds, spatial constructions" [Manovitch, 2018, 54].

\section{Five categories specific for digital visual culture}

In one of his books Lev Manovitch describes five categorial backgrounds, based on which he analyses new media [Manovitch, 2018, 41], but we think that those five are applicable to the analysis of all visual culture created based on computer technologies. In particular they characterize visual objects created by the neuronet Nikolai Ironov.

The first category studied by the author is digital representation. It is supposed that all objects regardless of the fact whether they were initially generated using a PC or became digitalized from analog sources, consist of a digital code, i. e. are digital representations of objects. Even if an object did not have a digital nature initially, it is subjected to the process of conversion, i. e. transfer of data into digital format (or digitalization). Nikolai Ironov uses a data base for generating its projects each element of which has its own digital code. Due to reading these codes, a neuronet performs commands quicker than a person, and offers a larger number of final products than a "live" designer.

A second category that appears to be important in analysis of digital visual culture is modularity. Objects of digital visual culture have similar (module) structure. "Media elements, i.e. images, sounds, forms or even specific actions, are presented as a range of discreet elements (usual or volume pixels, polyhedrons, code combinations, scripts). They store their initial logics and combine in larger objects, and they organize larger "units" preserving their initial structure" [Manovitch, 2018, 64].

Let's view the Microsoft bundle to understand this. Imagine, that we transfer an object to a Word document body, for example, graphical animation or video, that preserves its independence and may be edited using the same software where was created. The structure of an HTML document is also an example of modularity: beside the text it includes images, videos, VRML elements, films and other elements that exist on a PC or in the Internet independently. In other words, modularity specifies that objects of digital visual culture consist of independent elements, each of which may consist of smaller independent parts: and so on till the smallest "atoms" - pixels, volume pixels and symbols [Manovitch, 2018, 65].

Automation is a third category enabling understanding the essence of studied objects. Digital coding and modular structure enables automat- 
ing many processes used in the creation, management and access to objects of digital visual culture. "This means, that intentionality (direction of consciousness on a specified unit) specific to a human, may be partially excluded from creative process" [Manovitch, 2018, 66]. During the "work" of Nikolai Ironov, the analysis of a data base and following compilation of its results is not maintained by a person. A man is "beside" the creation of a final product. Despite process automation, the question on availability of special arrangements and algorithms for interpretation of generated senses is still important, i.e. during automatic compilation of independent data a generated object shall be "read" by a user. A neuronet shall create something "new" but at the same time act within the frameworks of specified senses.

Variability is a fourth category presented by Manovitch. An object created by a neuronet is not something completed in principle. On the contrary, it may exist in various and potentially unlimited versions. Strategy of "re-framing" (or "graphic saturation") described in previously falls into this category. Variability is natural for, for example, web-pages that are automatically generated from data bases, whose elements are combined in various variants having a stable structure.

Besides the variability of a form we may assure variability of content. For example, each reader of a hypertext selecting a specific link sees a partial fragment and each person interacting (let's imagine" with a digital installation) receives its version of a work.

The final category is transcoding which means transfer of something into another format. In the process of digitalization and computerization culture step-by-step appropriates this idea and uses it in relation to its own categories and concepts, replaces them on the level of sense and language by those that better match computer technologies [Manovitch, 2018]. Transcoding is also used by modern neuronets. For example, an image used for creation of a logo is of a situational nature and may transform as a result of compilations specified by a neuronet.

The author specifies that "mentioned categories illustrate general cultural trends passing through the process of total computerization, but not absolute laws" [Manovitch, 2018, 61]. That is why these categories are given in the article in order to better specify the general characteristics of digital visual culture. 


\section{Conclusions}

The basic nature of digital visual culture is visual image. Its influence became possible due to the development of computer technologies. The example of a specific neuronet showed that some processes related to generation of new visual objects can be analysed. In particular, five categories are specified enabling understanding arrangements used in the operation of the artificial neuron network (and digital culture in general). Yet, there are "blank" spots that are still open for the author. For example, may we considerthe "operation" of a neuronet an art? Or which advantage is more obvious - of the neuronet or of a person who created it?

It is supposed that such questions specify focuses defining other research studies and offer new development directions.

\section{Acknowledgment(s)}

This research was financially supported by the Russian Foundation for Basic Research (Grant No. 17-29-09136\18 "Multilingualism in the Era of Post-literacy: Philosophical and Cultural Studies and Methodological and Pedagogical Development of a Multilingual Education Model").

\section{References:}

1. M. V. Gabova. Vizual'naya kul'tura sovremennogo obshchestva (opyt tipologii). Chelovek. Kul'tura. Obrazovaniye [Visual culture of a modern society (typology experience). Human. Culture. Education.] № 2 (24) (2017), pp. 30-40. UDK 008+18.

2. L. Manovich. Yazyk novykh media. [Language of new media] Ad Marginem Press, Moscow (2018). ISBN 978-5-91103-411-5.

3. A. Danto. Chto takoye iskusstvo? [What is art?] Ad Marginem Press, Moscow (2018). ISBN 978-5-91103-397-2.

4. D. Dzhoslit. Posle iskusstva [Joselit D. After art] V-A-C press, Moscow (2017). ISBN 978-5-9906255-4-9. 